\title{
FRÊNULO LINGUAL: CLASSIFICAÇÃO E CONDUTA SEGUNDO ÓTICA FONOAUDIOLÓGICA, ODONTOLÓGICA E OTORRINOLARINGOLÓGICA
}

\author{
Lingual frenulum: classification and conduct \\ according to speech language pathologist, odontologist \\ and otorhinolaryngologist perspective
}

\author{
Suellen Ferro de Brito (1), Irene Queiroz Marchesan (2), Cyntia Monteiro de Bosco (3), \\ Alessandra Caxeta Alves Carrilho ${ }^{(4)}$, Maria Inês Rehder ${ }^{(5)}$
}

\section{RESUMO}

Objetivo: comparar a classificação e a conduta dos profissionais das áreas de fonoaudiologia, odontologia e otorrinolaringologia quanto ao frênulo de língua. Métodos: participaram dessa pesquisa 90 sujeitos, divididos em 3 grupos: 30 fonoaudiólogos, 30 odontólogos e 30 otorrinolaringologistas que responderam a dois protocolos, contendo quatro imagens de frênulos linguais. Os frênulos foram classificados como normal ou alterado. Quando a opção foi por alterado, foi indicada a conduta: cirúrgica, fonoterapia ou cirúrgica e fonoterapia. Os sujeitos também classificaram os frênulos de acordo com o tipo de inserção: normal, com inserção anteriorizada, curto ou curto com inserção anteriorizada. Resultados: com relação à caracterização de frênulos linguais como normais ou alterados, verificouse que a maioria dos profissionais teve opiniões semelhantes, caracterizando o frênulo normal como tal e o anteriorizado, o curto e o curto com inserção anteriorizada, como alterados. Com relação à conduta dos frênulos considerados alterados, a maioria dos odontólogos e otorrinolaringologistas, concordaram com a cirúrgica para todas as alterações dos frênulos. Para a maioria dos fonoaudiólogos, a conduta para o frênulo anteriorizado foi a fonoterapia e para os frênulos curto e curto com inserção anteriorizada, indicaram cirurgia seguida de fonoterapia. Quanto à classificação de acordo com o tipo de inserção, a opinião da maioria, foi coincidente nas três categorias profissionais. Conclusão: os achados mostraram coincidência na caracterização e na classificação dos frênulos linguais pelos profissionais das três áreas. Ocorreu divergência no que se referiu a conduta, cirúrgica com fonoterapia ou somente cirúrgica, para frênulo curto e frênulo curto com inserção anteriorizada.

DESCRITORES: Língua; Freio Lingual; Doenças da Língua; Procedimentos Cirúrgicos Bucais; Distúrbios de Fala; Fonoterapia

(1) Fonoaudióloga da Medical Center GO; Especialista em Motricidade Orofacial pelo CEFAC - Saúde e Educação.

(2) Fonoaudióloga; Diretora do CEFAC - Saúde e Educação; Doutora em Educação pela Universidade Estadual de Campinas.

(3) Fonoaudióloga do Só Riso GO; Especialista em Motricidade Orofacial pelo CEFAC - Saúde e Educação.

(4) Fonoaudióloga; Especialista em Motricidade Orofacial pelo CEFAC - Saúde e Educação.

(5) Fonoaudióloga; Parole Fonoaudiologia; Doutora em Distúrbios da Comunicação Humana pela Universidade Federal de São Paulo.

\section{INTRODUÇÃO}

O frênulo da língua vai da metade da face inferior da língua até o assoalho da boca. É uma grande prega mediana de túnica mucosa que passa da gengiva, recobrindo a face lingual da crista alveolar anterior, para a face póstero-inferior da língua, sendo constituído de tecido conjuntivo fibrodenso e, ocasionalmente, de fibras superiores do músculo genioglosso. Esta prega mucosa vai de uma parte mais fixa para uma parte com maior liberdade de movimentos ${ }^{1-4}$. 
A anquiloglossia, popularmente conhecida como "língua presa", é uma anomalia do desenvolvimento caracterizada por alteração no frênulo da língua resultando em limitações dos movimentos desta estrutura, podendo ainda gerar alterações de fala. A alteração da inserção pode variar desde a ponta da língua até o rebordo alveolar lingual sendo visível desde o nascimento até a idade adulta ${ }^{5-7}$.

Quando existe alteração do frênulo da língua pode-se encontrar como conseqüência, boca entreaberta, alterações oclusais e periodontais, dificuldade nos movimentos realizados pela língua, assim como postura baixa da mesma na cavidade oral. As funções de mastigar, deglutir e a produção dos sons da fala podem se alterar. As alterações de fala mais comumente encontradas são as distorções dos fones [s] e [z] e do vibrante alveolar simples em todas as suas posições. Como adaptações ou compensações durante a fala observa-se ainda a ocorrência da diminuição do espaço entre maxilares, aumento da salivação, movimentos mandibulares excessivos de lateralização e anteriorização, o que pode gerar imprecisão da fala. A amamentação e a fala são as alterações mais freqüentes quando o frênulo da língua se encontra alterado ${ }^{8-15}$.

Alguns profissionais intervêm cirurgicamente para corrigir as alterações do frênulo da língua, sendo mais freqüente odontólogos e otorrinolaringologistas o fazerem ${ }^{3-5,7,8}$. O fonoaudiólogo atua avaliando as condições do frênulo da língua via inspeção visual, verificando os movimentos da língua e avaliando as funções orofaciais de mastigação, deglutição e fala. Quando necessário sugere avaliação de outro profissional, intervenção cirúrgica ou fonoterapia para correção das alterações encontradas $2,6,9$.

A frenectomia nos bebês costuma ser indicada quando o frênulo da língua dificulta a movimentação da mesma ou a amamentação ${ }^{11-13}$. No entanto não é comum nos consultórios dos odontólogos ou dos otorrinolaringologistas aparecerem pacientes nessa faixa etária. Em crianças maiores a frenectomia lingual está indicada quando a inserção do frênulo pode provocar problemas periodontais, ou quando a falta de mobilidade da língua prejudicar a fala ${ }^{16,17}$.

A indicação de frenectomia ou da fonoterapia para melhor adaptação da função alterada está relacionada à formação do profissional e a seu conhecimento sobre o assunto, sendo utilizado, na maior parte das vezes, critérios pessoais ${ }^{3-5,7,8,12,17}$.

Existe considerável controvérsia entre os profissionais da saúde com relação a como classificar um frênulo como normal ou alterado. A controvérsia também existe com relação à indicação ou não de cirurgia $3-5,7,8,12,16,17$.
Sendo assim, o objetivo dessa pesquisa foi comparar o tipo de classificação e a conduta dos profissionais das áreas de fonoaudiologia, odontologia e otorrinolaringologia quanto ao frênulo da língua e suas alterações.

\section{MÉTODOS}

Este é um estudo de caráter transversal do qual participaram 90 sujeitos, divididos em três grupos: 30 fonoaudiólogos (G1), 30 odontólogos (G2) e 30 otorrinolaringologistas (G3).

Foram estabelecidos como critérios de inclusão, para todos os sujeitos, serem profissionais graduados em suas respectivas áreas há mais de cinco anos. No caso dos fonoaudiólogos deveriam ser especialistas em motricidade orofacial e no caso dos odontólogos e otorrinolaringologistas deveriam ser profissionais que atuassem na área de cirurgia.

Os sujeitos selecionados para esta pesquisa, responderam a dois protocolos especialmente elaborados para este fim, baseados nos critérios de Marchesan ${ }^{9,16}$. Os dois protocolos foram elaborados com as mesmas figuras, quatro imagens de frênulos utilizadas por Marchesan ${ }^{9}$, para classificação de frênulos linguais. As imagens foram dispostas em folhas separadas, em tamanho grande, e foram mostradas uma a uma, na mesma ordem de apresentação para todos os sujeitos. A cada imagem mostrada o profissional respondia à questão correspondente. As imagens já apresentadas eram separadas para que as respostas não fossem influenciadas por parâmetros comparativos (Figuras 1 a 4).

Para excluir-se a possibilidade de correção das respostas por comparação, os sujeitos classificaram as imagens somente uma vez. No protocolo 1 , os sujeitos classificaram os frênulos como normal ou alterado. Se optassem por alterado deveriam indicar a conduta (Figura 5). No protocolo 2, os sujeitos classificaram os frênulos como: normal, com inserção anteriorizada, curto ou curto com inserção anteriorizada (Figura 6).

A coleta de dados foi efetuada pessoalmente pelos mesmos avaliadores no local de trabalho dos sujeitos.

A presente pesquisa foi avaliada pelo Comitê de Ética e Pesquisa (CEP) do CEFAC - Saúde e Educação, aprovada sob o número $171 / 06$, considerada como sem risco e com necessidade do Termo de Consentimento Livre e Esclarecido.

Os dados coletados foram descritos e comparados inter e intra-sujeitos por meio de análise estatística com a aplicação do Teste de Qui-quadrado, ajustado pela Estatística de Fisher com nível de significância menor que $0,05 \%$. 


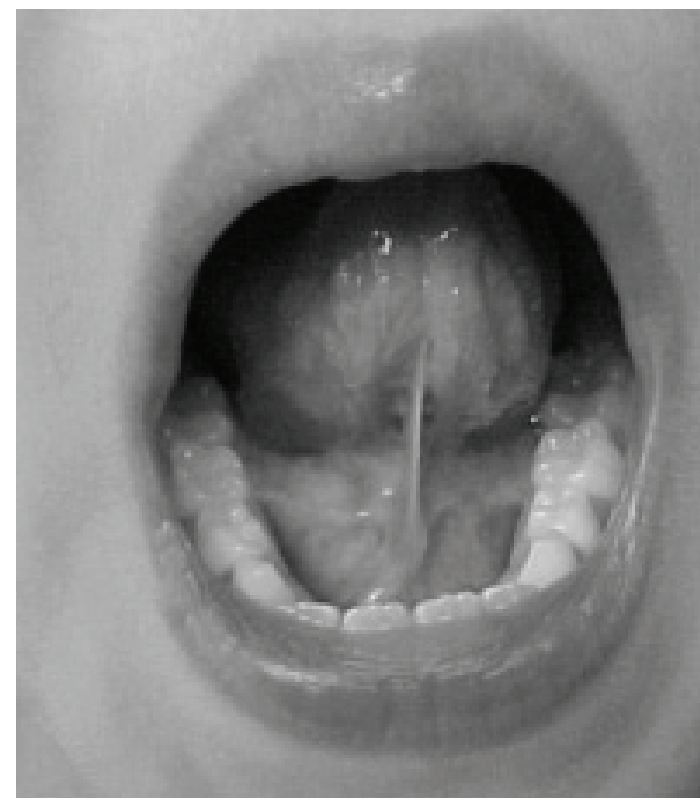

Figura 1 - Frênulo com inserção normal

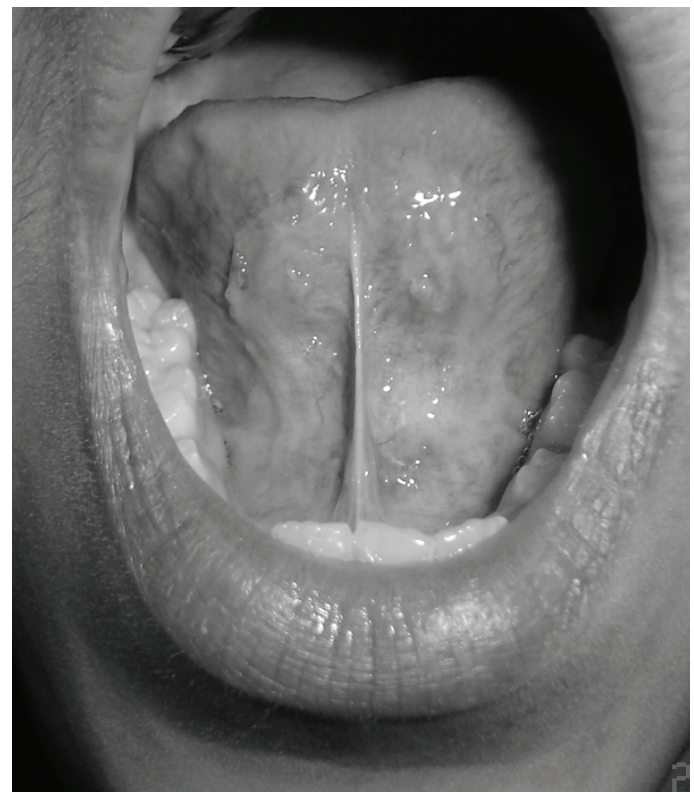

Figura 2 - Frênulo com inserção anteriorizada

\section{RESULTADOS}

Com relação à caracterização dos frênulos linguais, verificou-se $100 \%$ de coincidência com relação ao frênulo normal caracterizado como tal. $O$ frênulo anteriorizado foi caracterizado como alterado pela maioria dos fonoaudiólogos $(73,3 \%)$, dos odontólogos $(73,3 \%)$, e dos otorrinolaringologistas $(63,3 \%)$. O frênulo curto foi caracterizado como alterado pela totalidade dos fonoaudiólogos $(100 \%)$, pela maioria dos odontólogos $(93,4 \%)$ e

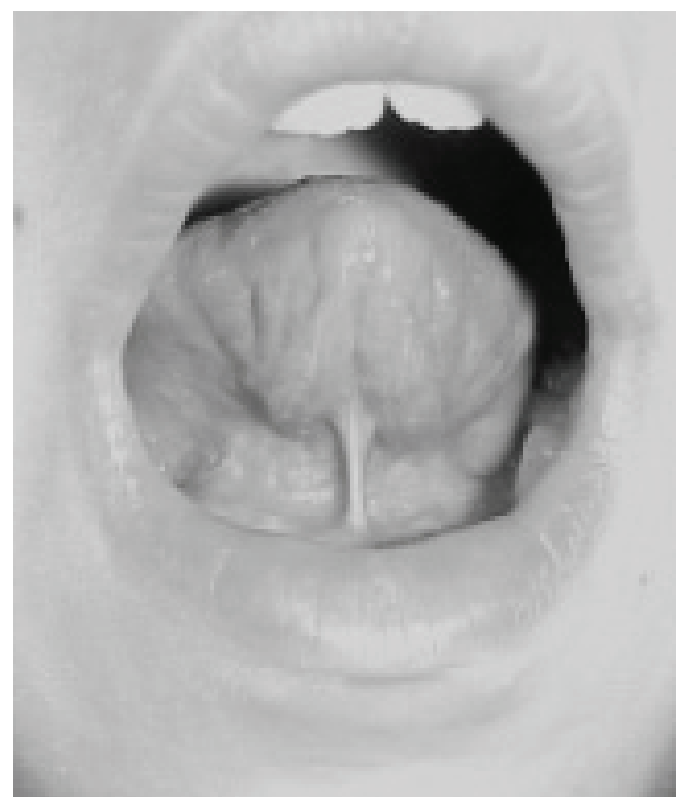

Figura 3 - Frênulo Curto

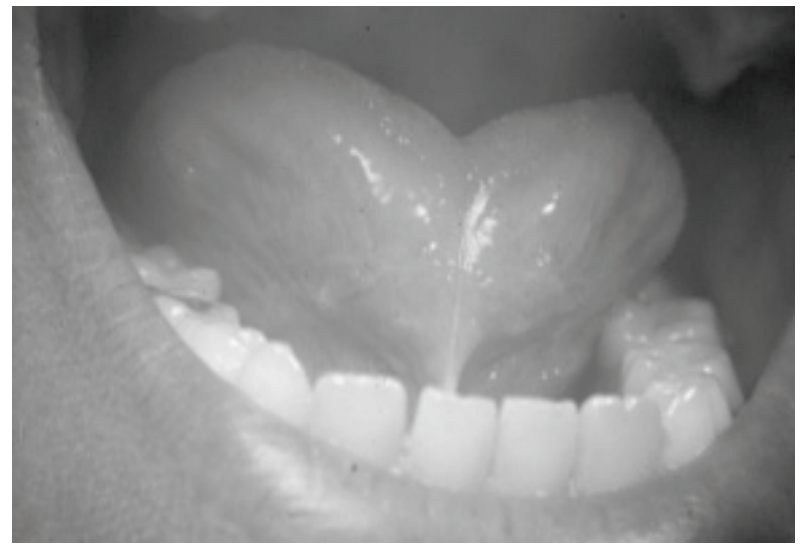

Figura 4 - Frênulo curto com inserção anteriorizada

dos otorrinolaringologistas $(96,7 \%)$. Houve coincidência total de respostas (100\%) entre os fonoaudiólogos, odontólogos e otorrinolaringologistas na classificação do frênulo curto e anteriorizado como sendo alterado (Tabela 1).

Ao verificar-se a conduta dos fonoaudiólogos, odontólogos e otorrinolaringologistas com relação ao frênulo anteriorizado, observou-se que a maioria dos fonoaudiólogos $(45,5 \%)$ indicou fonoterapia como a conduta principal nestes casos, seguida por cirurgia $(27,3 \%)$, cirurgia mais fonoterapia $(5 \%)$ e um sujeito $(4,5 \%)$ optou por nenhuma conduta. Ainda com relação à conduta frente aos frênulos anteriorizados, a maioria dos odontólogos (45,5\%) optou por cirurgia, 31,8\% por fonoterapia, 9,1\% por cirurgia mais fonoterapia e 3 sujeitos $(13,6 \%)$ optaram por nenhuma conduta nestes casos. 


\section{Protocolo 1}

Nome:

Profissão:

Frênulo lingual figura 1

( ) Normal

( ) Alterado

Conduta:

Frênulo lingual figura 2
( ) Normal
( ) Alterado

Conduta:

Frênulo lingual figura 3

( ) Normal

( ) Alterado

Conduta:

Frênulo lingual figura 4

( ) Normal

Conduta:

Figura 5 - Protocolo de classificação do frênulos como normal ou alterado e de indicação da conduta quando alterados

\section{Protocolo 2}

Nome:

Profissão:

Figura 1

( ) Frênulo normal

( ) Frênulo com inserção anteriorizada

( ) Frênulo curto

( ) Frênulo curto com inserção anteriorizada

Figura 2

( ) Frênulo normal

( ) Frênulo com inserção anteriorizada

( ) Frênulo curto

( ) Frênulo curto com inserção anteriorizada

Figura 3

( ) Frênulo normal

( ) Frênulo com inserção anteriorizada

( ) Frênulo curto

( ) Frênulo curto com inserção anteriorizada

Figura 4

( ) Frênulo normal

( ) Frênulo com inserção anteriorizada

( ) Frênulo curto

( ) Frênulo curto com inserção anteriorizada

Figura 6 - Protocolo de classificação de frênulos como: normal, com inserção anteriorizada, curto ou curto com inserção anteriorizada 
Tabela 1 - Caracterização de frênulos linguais por fonoaudiólogos, odontólogos e otorrinolaringologistas, como normais ou alterados $(n=90)$

\begin{tabular}{|c|c|c|c|c|c|c|c|}
\hline \multirow[t]{2}{*}{ Frênulo } & \multicolumn{2}{|c|}{ Fonoaudiólogos } & \multicolumn{2}{|c|}{ Odontólogos } & \multicolumn{2}{|c|}{ Otorrinolaringologistas } & \multirow{2}{*}{ Significância $(p)$} \\
\hline & freq. & $\%$. & freq. & $\%$ & freq. & $\%$. & \\
\hline \multicolumn{8}{|l|}{ Normal } \\
\hline Caracterizado Normal & 30 & 100,0 & 30 & 100,0 & 30 & 100,0 & \multirow{2}{*}{0,762} \\
\hline Caracterizado Alterado & 0 & 0,0 & 0 & 0,0 & 0 & 0,0 & \\
\hline \multicolumn{8}{|l|}{ Anteriorizado } \\
\hline Caracterizado Normal & 8 & 26,7 & 8 & 26,7 & 11 & 36,7 & \multirow{2}{*}{0,552} \\
\hline Caracterizado Alterado & 22 & 73,3 & 22 & 73,3 & 19 & 63,3 & \\
\hline \multicolumn{8}{|l|}{ Curto } \\
\hline Caracterizado Normal & 0 & 0,0 & 2 & 6,6 & 1 & 3,3 & \multirow{2}{*}{0,341} \\
\hline Caracterizado Alterado & 30 & 100,0 & 28 & 93,4 & 29 & 96,7 & \\
\hline \multicolumn{8}{|c|}{ Curto com Inserção Anteriorizada } \\
\hline Caracterizado Normal & 0 & 0,0 & 0 & 0,0 & 0 & 0,0 & \multirow{2}{*}{0,762} \\
\hline Caracterizado Alterado & 30 & 100,0 & 30 & 100,0 & 30 & 100,0 & \\
\hline
\end{tabular}

${ }^{*} \mathrm{p}<0,05$ (significativo)

A maioria dos otorrinolaringologistas $(42,1 \%)$ optou por conduta cirúrgica para os casos de frênulo anteriorizado, 31,6\% por fonoterapia, 5,2\% por cirurgia mais fonoterapia e $21,1 \%$ por nenhuma conduta (Tabela 2).
As condutas adotadas por fonoaudiólogos, odontólogos e otorrinolaringologistas foram bastante divergentes com relação aos frênulos curtos e aos frênulos curtos com inserção anteriorizada. Considerando os frênulos curtos, a maioria dos fonoau-

Tabela 2 - Conduta de fonoaudiólogos, odontólogos e otorrinolaringologistas, em relação aos frênulos alterados $(n=90)$

\begin{tabular}{|c|c|c|c|c|c|c|c|}
\hline \multirow{2}{*}{ Conduta } & \multicolumn{2}{|c|}{ Fonoaudiólogos } & \multicolumn{2}{|c|}{ Odontólogos } & \multicolumn{2}{|c|}{ Otorrinolaringologistas } & \multirow{2}{*}{ Significância (p) } \\
\hline & freq. & $\%$ & freq. & $\%$ & freq. & $\%$ & \\
\hline \multicolumn{8}{|l|}{ Anteriorizado } \\
\hline Fonoterapia & 10 & 45,5 & 7 & 31,8 & 6 & 31,6 & \multirow{4}{*}{0,326} \\
\hline Cirurgia & 6 & 27,3 & 10 & 45,5 & 8 & 42,1 & \\
\hline Cirurgia + Fonoterapia & 5 & 22,7 & 2 & 9,1 & 1 & 5,2 & \\
\hline Nenhuma & 1 & 4,5 & 3 & 13,6 & 4 & 21,1 & \\
\hline \multicolumn{8}{|l|}{ Curto } \\
\hline Fonoterapia & 8 & 26,7 & 8 & 28,6 & 6 & 20,7 & \multirow{4}{*}{$0,036^{*}$} \\
\hline Cirurgia & 10 & 33,3 & 13 & 46,4 & 15 & 51,7 & \\
\hline Cirurgia + Fonoterapia & 12 & 40,0 & 7 & 25,0 & 4 & 13,8 & \\
\hline Nenhuma & 0 & 0,0 & 0 & 0,0 & 4 & 13,8 & \\
\hline \multicolumn{8}{|c|}{ Curto com Inserção Anteriorizada } \\
\hline Fonoterapia & 1 & 3,3 & 1 & 3,3 & 0 & 0,0 & \multirow{4}{*}{$0,049^{*}$} \\
\hline Cirurgia & 11 & 36,7 & 18 & 60,0 & 18 & 60,0 & \\
\hline Cirurgia + Fonoterapia & 18 & 60,0 & 11 & 36,7 & 9 & 30,0 & \\
\hline Nenhuma & 0 & 0,0 & 0 & 0,0 & 3 & 10,0 & \\
\hline
\end{tabular}

${ }^{*} p<0,05$ (significativo) 
diólogos (40\%) optou por cirurgia mais fonoterapia, $33,3 \%$ somente por cirurgia e $26,7 \%$ somente por fonoterapia; os odontólogos em sua maioria $(46,4 \%)$ indicaram a cirurgia como primeira opção, $28,6 \%$ optou por fonoterapia e $25 \%$ por cirurgia mais fonoterapia; a maior parte dos otorrinolaringologistas $(51,7 \%)$ colocaram a cirurgia como primeira opção nestes casos, $20,7 \%$ fonoterapia, $13,8 \%$ cirurgia mais fonoterapia e $13,8 \%$ indicaram que não optariam por nenhuma das condutas indicadas. Quando solicitados a indicar a conduta para frênulos curtos com inserção anteriorizada, grande parte dos fonoaudiólogos (60\%) optou por cirurgia mais fonoterapia, $36,7 \%$ por cirurgia e 3,3\% por fonoterapia. Por outro lado, a maioria dos odontólogos $(60 \%)$ e dos otorrinolaringologistas (60\%) optaram por cirurgia como a conduta de eleição nos casos de frênulo curto com inserção anteriorizada (Tabela 2).

Com relação à classificação dos frênulos de acordo com o tipo de inserção, a totalidade dos fonoaudiólogos, odontólogos e otorrinolaringologistas concordaram com a classificação do frênulo com inserção normal como tal. Com relação ao frênulo com inserção anteriorizada, $83,3 \%$ dos fonoaudiólogos, $80 \%$ dos odontólogos e $70 \%$ dos otorrinolaringologistas o classificaram como tal. Houve também coincidência na classificação do frênulo curto para 93,3\% dos fonoaudiólogos, $90 \%$ dos odontólogos e para $83,3 \%$ dos otorrinolaringologistas. Quando solicitados a classificar o frênulo curto com inserção anteriorizada, $100 \%$ dos fonoaudiólogos, 93,3\% dos odontólogos e $83,3 \%$ dos otorrinolaringologistas o classificaram como tal (Tabela 3).

\section{DISCUSSÃO}

A definição do que seja um frênulo de língua normal é encontrada em livros de anatomia e dicionários e há concordância sobre o que é a normalidade ${ }^{1}$. Observou-se que nessa pesquisa isto

Tabela 3 - Classificação dos frênulos por fonoaudiólogos, odontólogos e otorrinolaringologistas, de acordo com o tipo de inserção $(n=90)$

\begin{tabular}{|c|c|c|c|c|c|c|c|}
\hline \multirow{2}{*}{ Frênulo/Classificação } & \multicolumn{2}{|c|}{ Fonoaudiólogos } & \multicolumn{2}{|c|}{ Odontólogos } & \multicolumn{2}{|c|}{ Otorrinolaringologistas } & \multirow{2}{*}{ Significância $(p)$} \\
\hline & freq. & $\%$ & freq. & $\%$ & freq. & $\%$ & \\
\hline \multicolumn{8}{|l|}{ Normal } \\
\hline Normal & 30 & 100,0 & 30 & 100,0 & 30 & 100,0 & \multirow{4}{*}{0,762} \\
\hline Anteriorizado & 0 & 0,0 & 0 & 0,0 & 0 & 0,0 & \\
\hline Curto & 0 & 0,0 & 0 & 0,0 & 0 & 0,0 & \\
\hline $\begin{array}{l}\text { Curto com Inserção } \\
\text { Anteriorizada }\end{array}$ & 0 & 0,0 & 0 & 0,0 & 0 & 0,0 & \\
\hline \multicolumn{8}{|l|}{ Anteriorizado } \\
\hline Normal & 4 & 13,4 & 3 & 10 & 6 & 20,0 & \multirow{4}{*}{0,549} \\
\hline Anteriorizado & 25 & 83,3 & 24 & 80,0 & 21 & 70,0 & \\
\hline Curto & 1 & 3,3 & 3 & 10,0 & 2 & 6,7 & \\
\hline $\begin{array}{l}\text { Curto com Inserção } \\
\text { Anteriorizada }\end{array}$ & 0 & 0,0 & 0 & 0,0 & 1 & 3,3 & \\
\hline \multicolumn{8}{|l|}{ Curto } \\
\hline Normal & 0 & 0,0 & 0 & 0,0 & 0 & 0,0 & \multirow{4}{*}{0,680} \\
\hline Anteriorizado & 0 & 0,0 & 0 & 0,0 & 1 & 3,3 & \\
\hline Curto & 28 & 93,3 & 27 & 90,0 & 25 & 83,3 & \\
\hline $\begin{array}{l}\text { Curto com Inserção } \\
\text { Anteriorizada }\end{array}$ & 2 & 6,7 & 3 & 10,0 & 4 & 13,4 & \\
\hline \multicolumn{8}{|c|}{ Curto com Inserção Anteriorizada } \\
\hline Normal & 0 & 0,0 & 0 & 0,0 & 0 & 0,0 & \multirow{4}{*}{0,148} \\
\hline Anteriorizado & 0 & 0,0 & 1 & 3,3 & 0 & 0,0 & \\
\hline Curto & 0 & 0,0 & 1 & 3,3 & 5 & 16,7 & \\
\hline $\begin{array}{l}\text { Curto com Inserção } \\
\text { Anteriorizada }\end{array}$ & 30 & 100,0 & 28 & 93,4 & 25 & 83,3 & \\
\hline
\end{tabular}

${ }^{*} \mathrm{p}<0,05$ (significativo) 
também ocorreu já que $100 \%$ dos profissionais ao verem a foto do frênulo normal o classificaram como tal. As alterações do frênulo da língua são diversas, e são descritas e classificadas por diferentes autores, de formas distintas não havendo concordância entre eles quanto ao nome que se deva dar e até quanto ao que é de fato uma alteração do frênulo da língua 3,5,6,9,12,14,16. Provavelmente isto ocorre, pois há grande variação da inserção do frênulo na língua, tanto quanto a seu local de inserção, como quanto ao seu comprimento. Além do local da inserção e do comprimento os frênulos podem ser mais ou menos espessos e com maior ou menor interferência na mobilidade e na postura da língua, assim como nas funções de mastigação, deglutição e fala 2,5,6,9-11,13,15-17.

Quanto a possíveis alterações do frênulo, observou-se que o frênulo anteriorizado foi caracterizado como alterado pela maioria dos fonoaudiólogos $(73,3 \%)$, odontólogos $(73,3 \%)$ e otorrinolaringologistas $(63,3 \%)$. Observou-se ainda, que a foto de frênulo anteriorizado foi a que mais gerou controvérsias na classificação como sendo normal ou alterado, pois houve maior divergência de opiniões, porém ressaltamos que esta diferença de definição não se apresentou estatisticamente significante entre os grupos estudados. A classificação utilizada neste trabalho foi a de Marchesan ${ }^{9}$, assim como as fotos contidas em sua proposta de avaliação ${ }^{16}$. Todos os profissionais tiveram uma única oportunidade de ver cada foto sem compará-las entre si. Frênulos chamados de longos ou de anteriorizados ${ }^{9,12,16}$ variam muito e são freqüentemente confundidos com os normais, sendo muitas vezes classificados como alterados não pelo seu aspecto mas sim pelas alterações oromiofuncionais encontradas $2,5,9-11,13,15,16$. De fato, não existe uma classificação anatômica única destas alterações, e nem sempre ela é primordial para a definição de um diagnóstico, já que os profissionais se reportam muito mais à questão funcional que a alteração do frênulo lingual pode causar, do que a padrões anatômicos de normalidade ${ }^{17}$.

Com relação ao frênulo lingual curto, $100 \%$ dos fonoaudiólogos, 93,4\% dos odontólogos e 96,7\% dos otorrinolaringologistas o caracterizaram como sendo alterado. O mesmo foi observado na caracterização do frênulo curto com inserção anteriorizada, havendo $100 \%$ de coincidência entre os profissionais ao caracterizá-lo como alterado (Tabela 1).

Frênulos curtos não causam no geral alterações de fala ou mesmo de mobilidade da língua. Clinicamente observa-se que línguas que têm frênulos curtos mantêm-se baixas, no assoalho da boca, o que aumenta a possibilidade de uma fala imprecisa ${ }^{9}$. Apesar deste tipo de frênulo não trazer grandes alterações funcionais, quando comparado com o frênulo anteriorizado ${ }^{16}$, o aspecto visual do frênulo curto é pior, e sendo assim, ele é mais facilmente identificado como alterado pelos profissionais, e foi exatamente o que ocorreu nesse trabalho onde a concordância visual para identificar os frênulos curtos foi maior do que a dos frênulos com inserção anteriorizada.

Com relação à conduta dos frênulos considerados alterados, a maioria dos odontólogos e otorrinolaringologistas, concordaram com a conduta cirúrgica para frênulos com inserção anteriorizada. Quando inquiridos a respeito da conduta com relação ao frênulo curto, observa-se que houve uma diferença estatisticamente significante na opinião de otorrinolaringologistas e fonoaudiólogos. A maioria dos otorrinolaringologistas apontou a cirurgia como conduta para os frênulos curtos e a maioria dos fonoaudiólogos apontou cirurgia seguida de fonoterapia. Não houve diferença estatisticamente significante com relação à conduta para frênulos curtos entre grupo de fonoaudiólogos e odontólogos e entre o grupo de odontólogos e otorrinolaringologistas (Tabela 2). Resultados semelhantes foram encontrados com relação à conduta para frênulos curtos com inserção anteriorizada. Neste item, também foi observado uma diferença estatisticamente significante na opinião de odontólogos e otorrinolaringologistas com relação aos fonoaudiólogos, sendo que a maioria dos odontólogos e otorrinolaringologistas apontou a cirurgia como conduta para os frênulos curtos com inserção anteriorizada e a maioria dos fonoaudiólogos apontou cirurgia e fonoterapia (Tabela 2). Achados da literatura permitiram observar que os fonoaudiólogos e odontólogos utilizam os critérios funcionais em maior escala, e buscam detalhar mais os $\operatorname{casos}^{2,9-11,13-16}$, enquanto os médicos preocupam-se mais com a prevalência, a descrição anatômica e com os procedimentos cirúrgicos $3,5-8,12$.

De acordo com a literatura, o frênulo é considerado normal quando a sua inserção vai da metade da face inferior da língua até o assoalho da boca. É considerado com inserção anteriorizada quando a inserção na face sublingual ocorre em qualquer ponto após o meio da face sublingual até a ponta da língua. $O$ frênulo é considerado curto, quando mesmo inserido no meio da face sublingual é de tamanho pequeno em relação à normalidade, muitas vezes dificultando o acoplamento da língua no palato duro. $O$ frênulo pode ainda, ser considerado curto com inserção anteriorizada, quando além de curto, apresentar a inserção anteriorizada ${ }^{9}$. Os resultados deste estudo mostraram que a maioria dos fonoaudiólogos, odontólogos e otorrinolaringologistas, mesmo utilizando apenas a avaliação 
visual via fotos para fazer a classificação do frênulo lingual (Tabela 3), mantiveram consenso entre eles com relação aos nomes propostos por Marchesan ${ }^{9}$. Segundo a mesma autora, qualquer avaliação e classificação do frênulo lingual são dependentes do conhecimento e dos critérios de avaliação de quem avalia, assim como, as condutas a serem tomadas também ficam dependentes da experiência e do conhecimento do avaliador ${ }^{16}$.

A maioria dos profissionais relatou que apenas por fotos não se obtêm uma avaliação fidedigna, pois a mobilidade e a postura da língua além da realização das funções de mastigação, deglutição e de fala caracterizariam melhor, se um frênulo é normal ou alterado.

Esse trabalho mostra que estudos mais aprofundados e objetivos com pesquisas controladas seriam necessários para que todos os profissionais que avaliam e tratam dos problemas do frênulo da língua pudessem, ao avaliar um frênulo de língua, classificar de forma igual, assim como indicar condutas semelhantes. Isto facilitaria que paciente e seus familiares, se sentissem mais confiantes e seguros para aceitar o que Ihes foi proposto. Muitas vezes os pacientes se sentem inseguros por obterem opiniões absolutamente contrárias sobre um mesmo problema.

\section{CONCLUSÃO}

Os achados desta pesquisa mostraram coincidência na caracterização e na classificação dos frênulos linguais por fonoaudiólogos, odontólogos e otorrinolaringologistas. Estes mesmos profissionais divergiram no que se referiu a conduta, cirúrgica e de fonoterapia ou somente cirúrgica, nos casos de frênulo curto e de frênulo curto com inserção anteriorizada.

\begin{abstract}
Purpose: to compare the classification and conduct of the professionals of speech language pathology, dentistry and otolaryngology fields regarding the lingual frenulum. Methods: 90 participants took part in this research, divided into 3 groups: 30 speech language pathologists, 30 dentists and 30 otolaryngologists who answered two protocols, with 4 images of the lingual frenulum. The lingual frenulum was classified as normal or altered. When the option was "altered", the indicated conduct was: surgery, speech therapy or surgery and speech therapy. The participants also classified the frenulum according to the type of insertion: normal, with anterior insertion, short or short with anterior insertion.

Results: in relation to the characterization of the lingual frenulum as normal or altered, we found that most professionals had similar views, characterizing the normal frenulum as normal, and the anterior, the short one and short with anterior insertion as altered. In relation to the conduct of the altered lingual frenulum, the majority of dentists and otolaryngologists agreed about the surgical conduct for all altered frenulum. For the majority of speech language pathologists, the conduct for anterior lingual frenulum was speech therapy, and for the short lingual frenulum and short with anterior insertion, they indicated surgery followed by speech therapy. For the classification according to the type of insertion, the opinion of the majority of the three professional categories was the same. Conclusion: the findings showed agreement in characterization and classification of the lingual frenulum by professionals of the three areas. There was disagreement in relation to the conduct: surgery and speech therapy or only surgery for short frenulum and short with anterior insertion.
\end{abstract}

KEYWORDS: Tongue; Lingual Frenulum; Tongue Diseases; Oral Surgical Procedures; Speech Disorders; Speech Therapy

\section{REFERÊNCIAS}

1. Sing S, Raymond DK. Dictionary of speechlanguage pathology. San Diego: Singular Publishing Group; 2000. p. 88

2. Lalakea ML, Messner AH. Ankiloglossia: the adolescent and adult perspective. Otolaryngol Head Neck Surg. 2003; 128:746-52.
3. Ballard JL, Auer CE, Khoury JC. Ankiloglossia: assessment, incidence, and effect of frenuloplasty on the breastfeeding dyad. Pediatrics. 2002; 110:63-8.

4. Pozza DH, Deyl JT, Cardoso ES, Cançado RP, Oliveira MG. Frenulectomia lingual: revisão de literatura e relato de caso clínico. Rev Odontol UFES. 2003; 5(2):19-25. 
5. Navarro NP, López M. Anquiloglossia en niños de 5 a 11 años de edad. Diagnóstico y tratamiento. Rev Cubana Estomatol. 2002; 39(3):3-7.

6. Garcia PMJ, Garcia MJM, Gonzalez GM. Prevalence of oral lesions in the 6 years-old pediatric population of Oviedo (Spain). Med Oral. 2002; 7:184-91.

7. Friggi MNP, Orsi RM, Chelotti A. Técnica cirúrgica pediátrica: frenectomia lingual. J Bras Odontopediatr Odontol. Bebe. 1998; 1(3):101-15.

8. Brinkmann S, Reilly S, Meara JG. Management of tongue-tie in children: a survey of paediatric surgeons in Australia. J Paediatr Child Health. 2004; 40(11): 600-5.

9. Marchesan IQ. Lingual frenulum: classification and speech interference. Int J Orofacial Myology. 2004; 30:31-8.

10. Messner AH, Lalakea ML. The effect of ankyloglossia on speech in children. Arch Otolaryngol Head Neck Surg. 2002; 127(6):539-45.

11. Berg KL. Tongue-tie (ankyloglossia) and breastfeeding: a review. J Hum Lact. 1990; 6(3):109-12.
12. Kotlow LA. Ankyloglossia (tongue-tie): a diagnostic and treatment quandary. Quintessence Int. 1999; 30(4):259-62.

13. Messner AH, Lalakea ML, Aby J, MacMahon J, Bair E. Ankyloglossia incidence and associated feeding difficulties. Arch Otolaryngol Head Neck Surg. 2000; 126(1):36-9.

14. Marchesan IQ. The speech pathology treatment with alterations of the stomatognathic system. Int $\mathrm{J}$ Orofacial Myology. 2000; 26:5-12.

15. Gonçalves CS, Ferreiro MC. Estudo da relação entre presença de frênulo lingual curto e/ou anteriorizado e a dorsalização de [r] na articulação da fala. Rev CEFAC. 2006; 8(1):56-60.

16. Marchesan IQ. Lingual frenulum: quantitative evaluation proposal. Int J Orofacial Myology. 2005; 31:39-48.

17. Ávila MI. As alterações do frênulo da língua na visão de médicos, cirurgiões dentistas e fonoaudiólogos do município de Itajaí/SC [dissertação] Paraná (PR): Universidade de Tuiuti do Paraná; 2005.

E-mail: suellenfb @bol.com.br 